\title{
O estabelecimento de metas como fator motivacional em contexto telecolaborativo
}

DOI: http://dx.doi.org/10.21165/el.v49i3.2610

\section{Camila Maria da Costa Kami ${ }^{1}$}

\section{Resumo}

Aprender uma língua estrangeira é um percurso longo e árduo, por essa razão, muitos aprendizes encontram dificuldade em se manterem motivados. Uma forma de sustentar a motivação é por meio do estabelecimento de metas de aprendizagem. O presente trabalho teve por objetivo investigar a motivação de duas interagentes brasileiras que participaram do Projeto Teletandem, um contexto virtual, autônomo e colaborativo, no qual falantes de línguas diferentes utilizam ferramentas tecnológicas para se comunicarem de forma síncrona, ajudando-o mutuamente a aprender a língua do outro. As participantes da pesquisa interagiram por um longo período de tempo, portanto, o estabelecimento de metas específicas foi primordial para que sustentassem a motivação ao longo do processo. Esta consiste em uma pesquisa qualitativa de natureza etnográfica, a qual utilizou questionários semiestruturados, entrevistas e transcrições das interações como instrumentos de coleta de dados.

Palavras-chave: aprendizagem de línguas; Teletandem; motivação.

1 Universidade Estadual Paulista "Júlio de Mesquita Filho" (UNESP), Araraquara, São Paulo, Brasil; camila.kami@fatec.sp.gov.br; https://orcid.org/0000-0002-6725-6196. 


\title{
Theestablishment of goalsasamotivationalfactorontelecollaborative context
}

\begin{abstract}
Learning a foreign language is a long and difficult process, therefore, many students find problems to be motivated. A way to keep motivation is to establish specific learning goals. This current paper aimed to observe the motivation of two Brazilian students, who took part in Teletandem Project, a virtual, autonomous and collaborative context, in which, speakers of different languages interact through a synchronous tool in order to learn the other's language. The participants interacted for a long period, therefore, the establishment of specific goals was essential to keep their motivation. It is a qualitative research of ethnographic nature, in which, semi-structure questionnaires, interviews and interactions transcriptions were used as data collecting tools.
\end{abstract}

Keywords: language learning; Teletandem; motivation.

\section{Introdução}

Apesar da infinidade de recursos disponíveis na internet e dos aplicativos para celular destinados ao ensino e aprendizagem de inglês, a grande maioria dos brasileiros apresenta baixa proficiência da língua inglesa; segundo o ranking do Índice de Proficiência em Inglês realizado pela EF, empresa de educação internacional especializada em intercâmbio, o Brasil ocupa a $53^{\circ}$ posição dentre 88 países que não possuem o inglês como língua nativa (MORENO, 2018).

Grande parte dos alunos utiliza a Internet para atividades sociais e recreativas, mas é preciso lembrar que as habilidades necessárias para tais atividades nem sempre são aquelas desejáveis em contextos virtuais de aprendizagem de línguas estrangeiras (LEs), os quais podem exigir o uso de um registro formal, competência intercultural e um conhecimento mais aprofundado da língua alvo (L-alvo) (O'DOWD, 2007).

Segundo Dooly e O'Dowd (2018), o aprendizado telecolaborativo como uma atividade pedagógica, que consiste na colaboração entre aprendizes que estejam em diferentes cidades ou países, tornou-se uma prática mais conhecida nesses últimos dez anos com o incremento de publicações sobre o tema e associações que possibilitam essa experiência. Esses contextos virtuais de aprendizagem se apresentam como uma oportunidade de aprender uma LE ou aprimorá-la.

O Teletandem, um contexto virtual, autônomo e colaborativo de ensino e aprendizagem de línguas por meio de ferramentas de comunicação síncrona, constitui um exemplo de 
aprendizado telecolaborativo. O projeto Teletandem Brasil: Línguas estrangeira para todos foi idealizado pelo Prof. Dr. João Antônio Telles e foi financiado pela FAPESP (Fundação de Amparo à Pesquisa do Estado de São Paulo) de 2006 a abril de 2010². Inicialmente, o projeto era realizado nos campi da Universidade Estadual Paulista "Júlio de Mesquita Filho" (UNESP) de Assis e São José do Rio Preto. Desde 2012, o projeto também está sendo desenvolvido no campus de Araraquara e encontra-se em fase de expansão para outras instituições como a UENP (Universidade Estadual do Norte do Paraná) e a URCA (Universidade Regional do Cariri).

Aranha e Cavalari (2014) discutem as modalidades de tandem, as quais também se aplicam ao contexto teletandem. Segundo as autoras, este pode ser institucional, semiinstitucional (quando essa característica se aplica apenas a um dos participantes) ou não institucional, somando às possibilidades de ser integrado ou não-integrado. De acordo com Aranha e Cavalari (2014, p. 185), o teletandem institucional integrado é considerado como uma atividade obrigatória "que os alunos devem cumprir dentro de determinada disciplina de língua estrangeira. Além disso, por estar vinculada a uma disciplina, a participação no teletandem pode ser avaliada pelo professor, conforme os critérios que ele estabelecer". O teletandem não-integrado é considerado como uma atividade extracurricular (TELLES, 2015b).

No início do projeto, quando as parcerias estavam sendo estabelecidas, o teletandem semi-institucional foi a modalidade mais praticada, uma vez que era apoiado pela UNESP, mas nem sempre os interagentes estrangeiros estavam vinculados a uma instituição. Além disso, existiram muitas dificuldades com relação ao uso dos recursos de áudio e vídeo. Não havia um tempo preestabelecido para o início e o fim das interações. Todos esses fatores poderiam repercutir de forma negativa na motivação dos interagentes.

Nessa época, apenas um aluno motivado e autônomo teria condições de interagir por um longo período de tempo. Hoje em dia, após 14 anos de projeto, as parcerias estão consolidadas, as interações são organizadas e agendadas pelos professores das instituições envolvidas, minimizando os insucessos. Como as interações duram de 4 a 5 semanas, no caso de Araraquara, acreditamos que há menos possibilidades de oscilações na motivação dos interagentes.

Neste trabalho, apresentamos duas parcerias de teletandem, português-inglês e português-espanhol, com o intuito de compreendermos a origem das metas das interagentes brasileiras e a avaliação que elas fazem sobre o alcance das mesmas ao final das interações.

2 Informações obtidas no site do Projeto Teletandem Brasil, disponível em: http://www. teletandembrasil.org/. 


\section{Teletandem: origem e princípios}

O teletandem originou-se do tandem, que surgiu na Alemanha no final dos anos 60, disseminando-se pela Espanha e outros países (VASSALLO; TELLES, 2009). Inicialmente, o tandem era presencial, o que restringia esta prática aos países da Europa em razão da proximidade entre os mesmos e a facilidade de encontrar falantes de outras línguas nesses territórios. No entanto, os avanços das novas tecnologias da informação e comunicação (NTICs) contribuíram para o surgimento do e-tandem, termo que se tornou mais comum a partir de 2000 (BRAMMERTS; CALVERT, 2003). 0 e-tandem era praticado por meio de ferramentas síncronas (MOOs, vídeo conferência, telefone) e assíncronas (e-mail). Entretanto, em razão da acessibilidade e praticidade, o e-mail foi a forma mais utilizada inicialmente.

O teletandem apresenta-se como um contexto virtual, autônomo e colaborativo "no qual dois falantes de línguas diferentes utilizam recursos de tecnologia VOIP (texto, voz e imagem de webcam) para ajudar o parceiro a aprender a sua língua materna (ou linguagem de proficiência)" (TELLES, 2015b, p. 604).

De acordo com Vassallo e Telles (2009), os princípios incorporados pelo teletandem, separação das línguas; reciprocidade e autonomia, tiveram sua origem no tandem. 0 primeiro pressupõe que o tempo de interação deve ser dividido entre as línguas. A reciprocidade implica a colaboração e o comprometimento com o aprendizado do parceiro. Por sua vez, a autonomia pressupõe a responsabilidade do interagente pelo seu próprio processo de aprendizagem. A respeito da relação entre autonomia e reciprocidade, Benedetti (2010, p. 39) argumenta: "[...] autonomia e reciprocidade adquirem um caráter inextricável, funcionando como peças imbricadas de um processo extremamente complexo".

\section{A motivação e 0 aprendizado de línguas}

Dörnyei (2000) afirma que as teorias sobre motivação, no geral, buscam elucidar três aspectos do comportamento humano: a escolha por uma dada ação, a persistência e o esforço despendidos. Por isso, a motivação é a razão de as pessoas decidirem fazer algo, por quanto tempo elas estarão dispostas a sustentar tal atividade e quanto lutarão para alcançar suas metas. 
O modelo do processo da motivação de L2 foi proposto por Dörnyei e Ottó (1998 apud DÖRNYEI, 2005) e reformulado por Dörnyei (2000, 2001 apud DÖRNYEI, op. cit.). A respeito deste modelo, Dörnyei (2005, p. 84, tradução nossa³) faz algumas considerações:

\begin{abstract}
Este modelo e suas elaborações (Dörnyei, 2000, 2001) dividem o processo motivacional em vários segmentos temporais discretos, organizados ao longo da progressão que descreve como os anseios e desejos iniciais são primeiramente transformados em metas e, então, operacionalizados em intenções, e como essas intenções são interpretadas, conduzindo (esperançosamente) ao cumprimento do objetivo e concluídas pela avaliação final do processo.
\end{abstract}

O modelo proposto pelo autor supracitado consiste de três fases, as quais resumimos. Primeiramente, a motivação precisa ser gerada, essa fase foi denominada motivação da escolha (choice motivation) em razão de conduzir à seleção do objetivo ou tarefa. Na segunda fase, a motivação gerada necessita ser mantida e protegida, esta foi referida como motivação de execução (executive motivation). A terceira e última fase consiste na retrospecção motivacional (motivational retrospection), que se caracteriza por uma avaliação retrospectiva feita pelo aprendiz acerca do processo.

Segundo Locke e Latham (1990 apud DÖRNYEI, 2001), a ação humana é impulsionada por propósitos e para que essa aconteça faz-se necessário o estabelecimento de metas e a persistência nas mesmas. Conforme Dörnyei e Ushioda (2011), a teoria de Locke e Latham foi desenvolvida no contexto organizacional e de trabalho, entretanto, esta também foi usada para estudar os contextos educacionais.

Dörnyei e Ushioda (op. cit.) argumentam que no caso de atividades que duram um longo período de tempo, como o aprendizado de uma língua, onde a meta de longo prazo consiste no domínio da L2, o estabelecimento de metas de curto prazo, por exemplo, fazer provas e ter bom rendimento, pode exercer uma poderosa função motivadora, uma vez que demonstram progresso, fornecem incentivos imediatos e feedback.

Locke (1996 apud DÖRNYEl; USHIODA, op. cit.) resume as descobertas dos trabalhos que focaram a teoria do estabelecimento de metas da seguinte maneira: i. as metas mais difíceis ocasionam melhores resultados; ii. as metas específicas e explícitas regulam o desempenho; iii. as metas específicas e difíceis conduzem a um desempenho alto; iv. o compromisso com as metas é maior quando estas são específicas e difíceis;

3 No original: "This model and its further elaboration (Dörnyei, 2000, 2001) broke down the motivational process into several discrete temporal segments, organized along the progression that describes how initial wishes and desires are first transformed into goals and then into operationalized intentions, and how these intentions are enacted, leading (hopefully) to the accomplishment of the goal and concluded by the final evaluation of the process". 
v. o alto comprometimento com as metas acontece quando o indivíduo se convence de que a meta é importante ou atingível. Da teoria de Locke (op. cit.), consideramos relevantes para o presente trabalho a especificidade das metas, as quais podem regular o desempenho e ocasionar compromisso. Outro ponto a ser considerado é que o comprometimento ocorre quando os indivíduos acreditam que a meta é importante e atingível.

A motivação no contexto do Teletandem foi abordada por Kami (2011, p. 167) e foi compreendida como um processo sujeito a oscilações e influenciado por fatores pessoais, socioculturais e contextuais.

Dentre os fatores pessoais encontram-se as expectativas, as metas, o Eu Ideal da L2 e a autonomia do aprendiz. Os fatores socioculturais abordam o ensino e o aprendizado de língua-cultura. Por sua vez, os fatores contextuais abrangem a reciprocidade e a influência da mediadora.

No presente estudo, conheceremos as expectativas e as razões que fizeram com que as interagentes brasileiras buscassem o projeto Teletandem e deram origem às metas. De acordo com Dörnyei (2005), o estabelecimento de metas ocorre na fase motivação da escolha. Durante a motivação de execução, apresentaremos alguns fatores que influenciaram a motivação das interagentes. Na fase da retrospecção motivacional, exibiremos a avaliação do processo pelas interagentes.

A seguir, qualificamos essa pesquisa, apresentamos o contexto, os participantes e os instrumentos utilizados para a coleta de dados.

\section{Metodologia}

O presente trabalho caracteriza-se como uma pesquisa qualitativa de natureza etnográfica, uma vez que confere visibilidade às diferentes perspectivas da pesquisadora e das interagentes brasileiras. Conforme André (2000), os participantes atribuem significados variados às suas experiências e vivências e o papel do etnógrafo consiste em revelá-los ao leitor. Foram utilizados os seguintes instrumentos de pesquisa: questionários semiestruturados, registros das interações e entrevistas.

Nesse estudo, foram analisadas duas parcerias: inglês-português e espanhol-português. Os interagentes estrangeiros eram dos Estados Unidos e do México e foram atribuídos nomes fictícios a fim de proteger suas identidades, William e Javier, respectivamente. As interagentes brasileiras denominadas Yasmim e Débora eram discentes do curso de licenciatura em Letras, regularmente matriculadas na UNESP de São José do Rio Preto. Ambas estavam envolvidas com pesquisa durante o período em que interagiram. 
As brasileiras realizaram o teletandem institucional não-integrado, ou seja, o projeto era apoiado pela universidade que disponibilizou um laboratório para as interações, mas as interações não faziam parte de nenhuma disciplina. Em razão dos parceiros estrangeiros não estarem vinculados a uma instituição, o teletandem configurou-se como nãoinstitucional. Nas duas parcerias, os interagentes estrangeiros interagiram do ambiente de trabalho.

Apenas a parceria de inglês-português realizou o teletandem prototípico, pois utilizou a webcam e o microfone, os quais possibilitaram interagir por videoconferência. No caso da parceria espanhol-português, não foi possível o uso dos recursos de áudio e vídeo na maioria das interações, em razão do parceiro estrangeiro não poder utilizar webcam no ambiente de trabalho. A parceria de espanhol-português utilizou o Windows Live Messenger e a de inglês-português, o Skype.

Yasmim, interagente da parceria inglês-português, interagia do Laboratório Teletandem, localizado na UNESP de São José do Rio Preto. Débora, da parceria espanhol-português, interagia duas vezes na semana. Em um dos dias, ela interagia do laboratório e, no outro, de sua casa.

Foi possível acompanhar a motivação das interagentes brasileiras por um período de cinco meses (de abril a agosto de 2010), na parceria de inglês-português, e sete meses aproximadamente (de maio a dezembro de 2009), na parceria de espanhol-português. Portanto, o foco do presente trabalho se centra unicamente na motivação das alunas brasileiras.

O questionário semiestruturado foi aplicado às interagentes brasileiras via correio eletrônico após nove interações, no caso da parceria de espanhol, e antes do início das sessões de teletandem da parceria de inglês. O objetivo deste instrumento foi levantar as razões que levaram as interagentes a participar do processo de ensino e aprendizagem via teletandem, bem como suas expectativas com relação ao aprendizado da LE.

A entrevista semiestruturada com ambas as interagentes brasileiras foi realizada quando as interações seencerraram eapós uma breve análise dos dados com o intuito de confirmar e esclarecer asserções levantadas durante o processo de análise das interações. As entrevistas duraram aproximadamente uma hora e meia e foram realizadas no campus da universidade onde as interagentes estudavam.

Na seção a seguir, a partir do modelo do processo da motivação de L2 proposto por Dörnyei (2005), analisaremos a motivação das interagentes brasileiras. 


\section{A motivação no contexto Teletandem}

As expectativas em relação ao aprendizado da LE e as razões que fizeram com que as aprendizes iniciassem o processo de interação via teletandem foram levantadas por meio de um questionário aplicado antes do início das interações, no caso da parceria de inglês-português e após nove interações da parceria de espanhol-português. Cumpre ressaltar que, apesar do questionário ter sido aplicado no momento em que as interações da parceria de espanhol-português estavam em andamento, os interagentes ainda estavam se conhecendo e negociando como ocorreriam as interações, por exemplo, o estabelecimento de temas para as sessões de teletandem. Portanto, a aplicação do questionário ocorreu em um momento em que as interagentes brasileiras exibiam uma motivação alta para ensinar e aprender via teletandem.

As razões que levaram Yasmim a se engajar no Projeto Teletandem foram o aprimoramento das habilidades da LI (linhas 3 e 4) e o aprendizado de vocabulário e aspectos culturais (linhas 4 e 5), como podemos observar no trecho a seguir:

(01) 1 A vontade de melhorar minhas habilidades na língua estrangeira. Sinto que tenho 2 dificuldades com a língua e por isso quero desenvolver minhas habilidades na língua, 3 aperfeiçoar. Acredito que interagir em Teletandem poderá me ajudar muito a melhorar o 4 listening, speaking, reading and writing. Além disso, aprenderei mais vocabulário e 5 também sobre aspectos culturais do país. Acredito que o Teletandem é uma ótima 6 oportunidade para praticar e desenvolver as habilidades na língua.

No segundo excerto, Yasmim menciona que decidiu interagir em teletandem a partir de uma sugestão do professor de inglês (linhas 7 e 8). Ela tinha muita dificuldade de compreensão oral, o que a prejudicava nas provas (linhas 2, 3 e 4), e não conseguia interagir nas aulas de LI (linhas 1 e 2). Além disso, ela se questionava como poderia ser professora de LI se tinha tanta dificuldade com a produção oral (linhas 5 e 6).

(02) 1 Bom, eu decidi no terceiro ano, fim do terceiro ano porque, eu tava co:m, muita dificuldade, 2 principalmente em, no speaking, interagir, em sala de aula. E o listening também, pra mim 3 era muito complicado, eu tinha muita dificuldade pra entender, na, durante as provas, e as 4 minhas notas não estavam boas. Eu queria melhorar, né, porque, pensei o ano que vem é o 5 quarto ano, e eu preciso melhorar esse meu inglês, como que eu vou ser uma professora? de 6 inglês? se eu tenho tanta dificuldade pra falar, em inglês. Assim, eu sabia mais a parte 
7 escrita, mas interagir eu era completamente travada. Aí o professor, sugeriu, por que você 8 não faz teletandem? talvez pode te ajudar, o professor, né, de inglês. Aí eu peguei e falei 9 assim, Ah, acho que vou tentar, né. Me inscrevi na página do teletandem, e dentro de um 10 mês, eu consegui um interagente.

Ao responder o questionário, Débora mencionou que buscou o Teletandem em razão de uma proposta de Estágio Básico, apresentada por sua professora. Esse fato que regulou sua motivação no momento em que se deparou com a falta de reciprocidade do parceiro, como será explicitado adiante.

Tanto as razões para buscar o Projeto Teletandem quanto as expectativas em relação ao aprendizado da LE impulsionaram o início do processo de ensino e aprendizagem via teletandem. Compreendemos expectativas como o que as interagentes buscavam aprender e as habilidades que desejavam desenvolver nesse contexto de ensino e aprendizagem virtual.

Com relação às expectativas do aprendizado da LE, Yasmim desejava, principalmente, aprimorar a compreensão e a produção oral e aprender vocabulário e aspectos culturais, o que pode ser depreendido do excerto a seguir:

(03) Espero melhorar minhas habilidades de speaking and listening principalmente. Quero conseguir me expressar melhor na língua estrangeira e poder entender a língua durante a comunicação. Além disso, espero expandir meu vocabulário e aprender mais sobre a cultura inglesa.

As expectativas de Débora com relação ao aprendizado da língua espanhola em teletandem consistiam no aprendizado de vocabulário, dos aspectos culturais do México e da variante mexicana, conforme pode ser observado no excerto abaixo.

(04) Pretendo aprender palavras novas, algo sobre a cultura e tudo o que ele quer me ensinar, pois meu interagente é mexicano e na faculdade aprendemos mais sobre a Espanha, então creio que tenho diferentes coisas para aprender com ele sobre o Espanhol Mexicano.

Por meio do modelo do processo da motivação de Dörnyei (2005), compreendemos que as vontades e os desejos iniciais são transformados em metas na primeira fase do modelo, denominada de motivação da escolha. Nessa fase, a especificidade da meta é muito importante para que o aprendiz tenha em mente o quanto precisará se esforçar para alcançá-la. Em seguida, as metas são convertidas em intenções, as quais irão 
conduzir ao cumprimento da meta, concluindo-se com a avaliação final do processo. O autor distingue meta de intenção, afırmando que esta última envolve compromisso.

As metas de Yasmim consistiam no aprimoramento da compreensão e produção oral e aprendizado de vocabulário e aspectos da cultura norte-americana. As metas de Débora resumiam-se no aprendizado de vocabulário, dos aspectos culturais do México e da variante mexicana e no desenvolvimento do Estágio Básico. No decorrer das interações, torna-se evidente que a meta principal de Débora passa a ser o desenvolvimento do Estágio Básico em razão da quebra de reciprocidade por parte do parceiro que, em muitas ocasiões, fornecia um input que continha erros ortográficos, gramaticais e de acentuação. Além disso, ele se atrasava com frequência e não compareceu a algumas sessões.

Considerando os pontos levantados por Locke (1996 apud DÖRNYEl; USHIODA, 2011) a respeito do estabelecimento de metas, verificamos que tanto Yasmim quanto Débora consideraram a importância do Teletandem para o aprendizado de línguas. Além disso, as interagentes brasileiras acreditaram que tais metas seriam atingíveis, uma vez que estabeleceram objetivos específicos de aprendizagem. Segundo Locke (op. cit.), o comprometimento ocorre quando se acredita que determinada meta é importante e atingível.

A especificidade das metas regula o desempenho e acarreta um maior compromisso, conforme Locke (1996 apud DÖRNYEl; USHIODA, 2011). A especificidade das metas foi fundamental para regular o desempenho das interagentes, uma vez que estavam cientes de seus objetivos de aprendizagem e, por isso, tinham condições de pedir auxílio aos seus parceiros a fim de atingirem suas metas.

Ao final das interações via teletandem, durante a entrevista, perguntamos às interagentes se a experiência vivenciada correspondeu às suas expectativas e se haviam alcançado suas metas. Ao ser questionada a esse respeito, Yasmim menciona que teve uma grande melhora, agora consegue comunicar-se em Ll; chegou até a apresentar seminários na L-alvo e suas notas melhoraram, informações que podem ser conferidas no excerto abaixo:

(05) Eu acredito que sim. Eu achei que eu melhorei muito, do ano passado pra cá. Agora eu consigo me comunicar na sala de aula, eu falo com o professor, eu apresentei seminários esse ano. $\mathrm{O}$ ano passado foi muito difícil apresentar seminário. Apresentei um, e fiquei muito assim, nervosa. Esse não, eu me soltei mais, eu consegui falar bem no seminário, tirar uma nota melhor, minhas provas melhoraram, eu achei. Meu desempenho na, aula melhorou. 
A principal meta de Yasmim era aprimorar a compreensão e a produção oral, o que foi alcançado graças ao comprometimento de William com seu aprendizado. Ele estava atento à pronúncia de Yasmim, corrigindo-a sempre que necessário. Dessa forma, a maneira como William a ajudou a aprender a LI foi ao encontro de suas expectativas, repercutindo de forma positiva em sua motivação.

No excerto abaixo, podemos perceber que as interações em teletandem aumentaram a autoestima da interagente, que não se sentia capaz de se comunicar em sala de aula, ela ficava inibida diante de seus colegas que já haviam estudado a LI durante oito ou dez anos (linhas 3, 4, 5, 6 e 7). É interessante observar nas linhas 8, 9 e 10 como William a encoraja a comunicar-se na $\mathrm{LI}$ ao mencionar que ele a compreende.

(06) 1 [...] Eu me senti, é, capaz de me comunicar em língua inglesa, porque antes eu tinha uma 2 autoestima muito baixa. Porque na sala a gente tem muitos níveis, tem as pessoas, os alunos 3 tem muitos níveis diferentes, e a maior parte da turma já tinha feito inglês durante oito anos, 4 dez anos, então tinha já um nível avançado, e eu, como nunca tinha feito aula particular, 5 vim da escola pública, eu tinha muito mais dificuldade. Então aí eu não tinha, aí eu tinha 6 muita vergonha também em, conversar durante as aulas, porque eu via meus amigos falando 7 tão bem, e eu tinha vergonha de falar. Aí depois, que eu comecei a interagir com ele, eu 8 percebi que eu fiquei mais segura. Porque ele falava: "Eu consigo te entender, não, você 9 fala até bem". Eu falei: "Sério? Ah, que bom, você tá conseguindo me entender, então eu 10 não sou tão ruim assim". Então, eu fui me soltando mais, fui ficando mais segura. Eagora, 11 eu não tenho mais medo de ficar errando. Esse ano eu me arrisquei muito mais durante as 12 aulas, quando eu queria falar, eu falava.

Débora avaliou que seu aprendizado foi mais cultural e considerou uma experiência importante, a qual possibilitou o desenvolvimento de seu projeto de Estágio Básico e, além disso, contribuiu para a construção do conhecimento acerca da língua espanhola. No entanto, é possível perceber um certo descontentamento em relação ao aprendizado da gramática, o que fica claro na linha 3 do excerto a seguir:

(07) 1 É então, acho que, como eu já disse também foi mais um aprendizado cultural, do que 2 gramatical, assim em relação à língua espanhola, e:, acho que eu pude aprender, é, mais 3 coisa sobre o México, né, nada muito, relevante em relação à gramática da língua espanhola. 4 Foi importante, é, foi importante pro meu projeto de estágio e foi importante pra mim assim, 5 porque, dependendo do que eu for fazer agora, vai ser, tipo essa foi minha base. 
Podemos dizer que as metas de Débora foram parcialmente atingidas, visto que ela aprendeu sobre aspectos culturais do México e conseguiu finalizar o Estágio Básico. Embora não tenha mencionado sobre o interesse com relação ao aprendizado da gramática quando o questionário foi aplicado, no excerto abaixo, Débora revela esse interesse (linha 3) e pede ao parceiro que selecione algum tópico gramatical para a próxima interação (linha 8).

(08) 1 Débora diz:

2 sí .. entonces es tu que deves escojer el tema que vamos hablar ..

3 a mí me gustaría aprender algo de gramática, sí?

$4[\ldots]$

5 Javier diz:

6 que te parece transporte

7 Débora diz:

8 por hoy puede ser, pero a para la proxima clase pudes me enseñar algo de gramática?

9 Javier diz:

$10 \mathrm{OK}$

$\mathrm{Na}$ ocasião da entrevista, Débora relatou que compreendeu que seu parceiro não conseguia Ihe explicar determinados aspectos gramaticais com clareza e não considerou isso como um aspecto negativo. Ela acredita que Javier fez o que estava ao seu alcance (linha 4 do excerto 10) e teria se frustrado se ele fosse um professor de línguas e não tivesse ensinado a gramática para ela (linhas 5, 6 e 7).

(09) 1 É, eu tive sim, só como, eu já comentei em relação à gramática, que não tanto, mas, assim a 2 partir do momento que eu comecei, que eu passei a conhecer o meu interagente também né, 3 porque às vezes a gente espera tanto de uma pessoa, mas não conhece a pessoa, então como 4 eu te falei, eu acho que dentro das possibilidades dele, ele fez o que ele pode, entendeu? 5 Como eu já disse também, se fosse talvez uma pessoa que, um professor de línguas e não 6 tivesse me ensinado, aí sim eu acho que eu teria ficado mais frustrada, mas como ele não 7 era, não tinha o porquê, entendeu?, de eu me sentir defasada assim, em relação a isso.

Cumpre ressaltar que, mesmo diante da falta de comprometimento do parceiro com seu aprendizado em algumas ocasiões, Débora menciona que aprendeu com Javier e que ele se empenhava em ajudá-la. No entanto, ele fornecia um input de má qualidade em alguns momentos, o que não possibilitou que Débora aprimorasse o seu conhecimento acerca da gramática. 
Nesta seção, apresentamos as razões que fizeram com que as aprendizes decidissem interagir via teletandem, bem como suas expectativas com relação ao aprendizado da LE. Além disso, argumentamos que essas motivações iniciais deram origem às metas, que, por sua vez, repercutiram na motivação das interagentes, uma vez que direcionaram o comportamento de aprendizado em direção ao cumprimento da meta.

A maneira como William ajudou Yasmim a aprender a LI foi ao encontro de suas expectativas, motivando-a e conduzindo-a ao cumprimento de sua meta principal, o aprimoramento da compreensão e produção oral. Em contrapartida, as metas de Débora foram parcialmente alcançadas, uma vez que ela conseguiu finalizar o Estágio Básico e aprendeu aspectos culturais acerca do México; no entanto, ela desejava aprender também sobre a gramática. Dessa forma, podemos afirmar que a maneira como Javier ajudou Débora a aprender o espanhol não foi ao encontro de suas expectativas e acabou desmotivando-a. Ao final das interações, ela não solicitava mais correção ao parceiro, deixou de selecionar temas para as interações, não atribuía mais tarefa à Javier. Ela, de fato, estava preocupada em finalizar o Estágio Básico, por isso, afirmamos que a meta de concluir o estágio tornou-se a principal, fazendo com que ela continuasse a interagir via teletandem; podemos dizer que esta meta regulou o comportamento de aprendizado de Débora.

\section{Considerações finais}

No presente estudo, analisamos a motivação de duas interagentes brasileiras, Yasmim, da parceria inglês-português, e Débora, da parceria espanhol-português. Uma vez que Dörnyei (2005) afırma que os anseios e desejos iniciais são transformados em metas, é possível dizer que as razões que levaram Débora e Yasmim a se engajarem no Projeto Teletandem, bem como suas expectativas com relação ao aprendizado da LE, deram origem às metas.

O estabelecimento de metas mostrou-se de extrema importância para a sustentação da motivação das interagentes, especialmente no caso de Débora. Como nos lembram Locke e Lathan (1990 apud DÖRNYEI, 2001) e Dörnyei e Ushioda (2011), as metas impulsionam e direcionam a ação. Além disso, a especificidade das mesmas pode guiar o comportamento e regulá-lo.

As metas de Yasmim consistiam no aprimoramento da compreensão e produção oral, aprendizado de vocabulário e aspectos da cultura norte-americana. Débora tinha como meta expandir seu vocabulário, aprender aspectos culturais e a variante do México e desenvolver o Estágio Básico. No entanto, ao longo do processo de ensino e aprendizagem via teletandem, a meta concernente ao desenvolvimento do estágio se sobressaiu, tornando-se a principal. 
Débora desejava realizar uma Iniciação Científica, para isso, precisava desenvolver o Estágio Básico. Em razão da falta de reciprocidade por parte de seu parceiro de teletandem em alguns momentos, o que comprometeu as metas que havia estabelecido para o aprendizado da LE, finalizar o estágio tornou-se a meta principal.

Com relação ao alcance das metas, Yasmim disse que realmente melhorou as habilidades de listening e speaking, sentindo-se mais confiante ao se expressar em LI. Débora mencionou que aprendeu vários aspectos culturais acerca do México, mas gostaria de ter aprimorado seu conhecimento sobre a gramática.

Cabe ressaltar que as interagentes analisadas neste trabalho interagiram por um longo período de tempo, as interações da parceria de inglês-português duraram 5 meses e as da parceria de espanhol-português, 7 meses aproximadamente. Por essa razão, houve oscilação na motivação da interagente da parceria de espanhol-português em razão da falta de comprometimento do parceiro com seu aprendizado, o qual oferecia um input de má qualidade, se atrasava para as interações e deixou de comparecer a algumas sessões.

Atualmente, no campus da UNESP de Araraquara, as interações duram em torno de 4 a 5 semanas, o que pode reduzir as oscilações na motivação dos interagentes. Além disso, como as interações são agendadas e acompanhadas pelas professoras de ambas as instituições, os imprevistos, como a ausência de um interagente, são rapidamente contornados pelas professoras e pelos monitores do projeto da instituição brasileira. Faz-se necessário investigar, nesse contexto, como se comporta a motivação dos interagentes brasileiros.

\section{REFERÊNCIAS}

ANDRÉ, M. E. D. A. Etnografia da prática escolar. 4. ed. Campinas: Papirus, 2000.

ARANHA, S.; CAVALARI, S. M. S. A trajetória do projeto Teletandem Brasil: da modalidade institucional não-integrada à institucional integrada. The ESPecialist, São Paulo, v. 35, n. 2, p. 183-201, 2014. Disponível em: http://revistas.pucsp.br/index.php/ esp/article/view/21467/15694. Acesso em: 25 jul. 2018.

BENEDETTI, A. M. Dos princípios de tandem ao teletandem. In: BENEDETTI, A. M.; CONSOLO, D. A.; VIEIRA-ABRAHÃO, M. H. (org.). Pesquisas em ensino e aprendizagem no Teletandem Brasil: línguas estrangeiras para todos. Campinas: Pontes, 2010. p. 21-45.

BRAMMERTS, H.; CALVERT, M. Learning by communicating in tandem. In: LEWIS, T.; WALKER, L. (ed.). Autonomous Language Learning In-Tandem. Sheffield, UK: Academy Electronic Publications, 2003. p. 45-60. 
DOOLY, M. A.; O'DOWD, R. Telecollaboration in the foreign language classroom: A review of its origins and its application to language teaching practice. In: DOOLY, M. A.; O'DOWD, R. (ed.). In this together: Teacher's experiences with transnational, telecollaborative language learning projects. Bern: Peter Lang, 2018. p. 11-34. Disponível em: https:// www.peterlang.com/view/9783034335348/chapter01.xhtml. Acesso em: 25 jul. 2018.

DÖRNYEI, Z. Motivation and 'self-motivation'. In: DÖRNYEI, Z. The psychology of the language learner: Individual differences in second language acquisition. New Jersey: Lawrence Erlbaum Associates Publishers, 2005. p. 65-119.

DÖRNYEI, Z. Teaching and researching motivation. Harlow, England: Pearson Education Limited, 2001. (Applied Linguistics in Action)

DÖRNYEI, Z. Motivation in action: Towards a process-oriented conceptualisation of student motivation. British Journal of Educational Psychology, Great Britain, n. 70, p. 519$538,2000$.

DÖRNYEI, Z.; USHIODA, E. Teaching and researching motivation. 2. ed. United Kingdom: Pearson Education Limited, 2011. (Applied Linguistics in Action Series)

KAMI, C. M. C. A motivação na aprendizagem de língua estrangeira via Teletandem. 2011. Dissertação (Mestrado em Estudos Linguísticos) - Instituto de Biociências, Letras e Ciências Exatas, Universidade Estadual Paulista "Júlio de Mesquita Filho", São José do Rio Preto, 2011.

MORENO, A. C. Brasil não avança em ranking mundial de proficiência em inglês e perde 12 posições. G1, 30 out. 2018. Educação. Disponível em: https://g1.globo.com/ educacao/noticia/2018/10/30/brasil-nao-avanca-em-ranking-mundial-de-proficienciaem-ingles-e-perde-12-posicoes.ghtml. Acesso em: 19 ago. 2019.

O'DOWD, R. (org.). Foreign language education and the rise of online communication: A review of promises and realities. In: O'DOWD, R. Online intercultural exchange: An introduction for foreign language teachers. Clevedon: Multilingual Matters LTD, 2007. p. 17-37.

TELLES, J. A. Teletandem and performativity. Revista Brasileira de Linguística Aplicada, Belo Horizonte, v. 15, n. 1, p. 1-30, 2015a. Disponível em: http://www.scielo.br/scielo. php?script=sci_arttext\&pid=\$1984-63982015000100001\&lng=en\&nrm=iso\&tlng=en . Acesso em: 25 jul. 2018. 
TELLES, J. A. Learning foreign languages in teletandem: Resources and strategies. DELTA, São Paulo, v. 31, n. 3, p. 603-632, 2015b. Disponível em: http://www.scielo.br/ scielo.php?script=sci_arttext\&pid=S010244502015000400603\&lng=en\&nrm=iso. Acesso em: 25 jul. 2018.

VASSALO, M. L.; TELLES, J. A. Ensino e aprendizagem de línguas em tandem: princípios teóricos e perspectivas de pesquisa. In: TELLES, J. A. (org.). Teletandem: Um contexto virtual, autônomo e colaborativo para aprendizagem de línguas estrangeiras no século XXI. Campinas: Pontes, 2009. p. 21-42. 